\title{
IMPROVING TEST-TAKING SKILLS OF LD ADOLESCENTS
}

\section{Geraldine Markel}

More and more learning-disabled adolescents are now being served at the high school level. Usually these students have access to the services of a resource room and attend classes with their nonhandicapped peers. Once integrated in math, English, or civics courses, however, they are then faced with the difficult problem of taking tests, for which many do not have the necessary skills. To increase their test-taking skills they must learn systematic procedures through a team effort, including special education consultants, regular education teachers, and supportive personnel.

Recent findings in behavioral psychology provide a basis for a multicomponent model to improve the test-taking skills of adolescents with learning disabilities. As with other complex activities, such efforts require first an analysis of the problems that present barriers to effective test taking and then a specification of procedures to alleviate the problems.

\section{Test-Taking Problems}

The test-taking problems faced by students with learning disabilities are illustrated by their comments: "I don't know

Geraldine Markel, PhD, is an assistant professor in the program in Special Education, School of Education, at the University of Michigan, Ann Arbor, Michigan 48109. 
what I'm supposed to do"; "This test isn't fair"; "I don't know how to do this"; "I read the book but I don't remember"; "I'll fail"; and "I'm afraid."

Such remarks reflect problems that involve five broad classifications of student skills: (1) anxiety-management skillsmanaging the tension and anxiety created by tests; (2) interpersonal skills-asking either for clarification of instructions or for assistance; (3) problem-solving skills-organizing cognitive behavior in order to complete the test accurately; (4) study and test-taking skills-preparing for and taking examinations in an effective manner; and (5) self-management skills-controlling and regulating one's behavior. Because these skills interact with and influence each other, skill clusters may be taught separately or as an integrated package. The extent, intensity, and order of the instruction depend on the needs of the student.

\section{Anxiety Management}

Test anxiety produces symptoms that hinder a student's ability to perform adequately on tests. Anxiety may be experienced on the cognitive level as negative thoughts or images; on the physiological level by increased heart rate, respiration, and perspiration; and on the motor level by shaking, stuttering, and muscle tension. Test-anxious students fail to pay attention to important aspects of a test, suffer from high emotional arousal, and allow irrelevant thoughts to intrude upon their performance (Wine 1971). A variety of behavior-oriented approaches have been developed to deal with test taking, primarily for college-age students, but some studies have advocated that interventions either to prevent or to treat test anxiety should begin early in a student's school life.

Given the characteristics of learning-disabled adolescents and their usual history of failure, teachers should assume that anxiety about tests poses a considerable problem to them. Moreover, they frequently do not discuss their anxiety but demonstrate it in a variety of other ways, such as: avoidance (absence, tardiness, excuses), direct expressions (crying, refusing, leaving), physical complaints (headaches, nausea), or lack of attention (staring, fidgeting). Ignoring such problems does not usually make them go away. Students exhibiting symptoms of test anxiety should be referred or evaluated by the teachers, using suitable assessments (for example, Spielberger et al. 1977), and when necessary provided with training so that cues which trigger such reactions may be reduced. 


\section{Problem-solving Skills}

Problem solving involves a complex set of skills with which learning-disabled children often have difficulty, especially when faced with test situations. Students who demonstrate effective problem-solving skills talk to themselves in ways different than those of children who are impulsive and hyperactive (Meichenbaum 1977). Observation indicates that some hyperactive and impulsive children rarely talk to themselves and if they do, they do so in inappropriate and dysfunctional ways.

Several studies focusing on self-instructional training procedures indicate that hyperactive, impulsive children can be taught to think before they act and to bring their behavior under their verbal control. A five-step self-instruction sequence outlined by Meichenbaum (1977) provides a guide and method of talking to oneself which is effective in helping hyperactive and impulsive children solve problems: (1) cognitive modeling (an adult performing a task while talking aloud); (2) overt, external guidance (the child performs the same task under the direction of the adult's instructions); (3) over self-guidance (the child performs the task while instructing him- or herself aloud); (4) quiet self-guidance (the child whispers instructions to him- or herself as he or she goes through the task); and (5) covert selfinstructions (the child performs the task while guiding his performance via private speech).

This procedure can also be used to teach the student problem-solving skills for individual test items (for example, math problems). The teacher should provide the student with instruction and practice in self-instructional training in the resource room and then provide systematic feedback on the successful use of this technique with tests in the resource or regular room. The feedback to the student on successful performance should be clear and specific. For example, an audio or videotape recording provides proof that a process as complicated as cognitive functioning or problem solving is systematic, controllable, and improvable.

Assertiveness

Assertiveness can be defined as standing up for one's rights without violating the rights of others. As applied to learningdisabled adolescents and their problem of test taking, it means that students must ask questions about directions or format, voice concern about appropriateness of test items, and share 


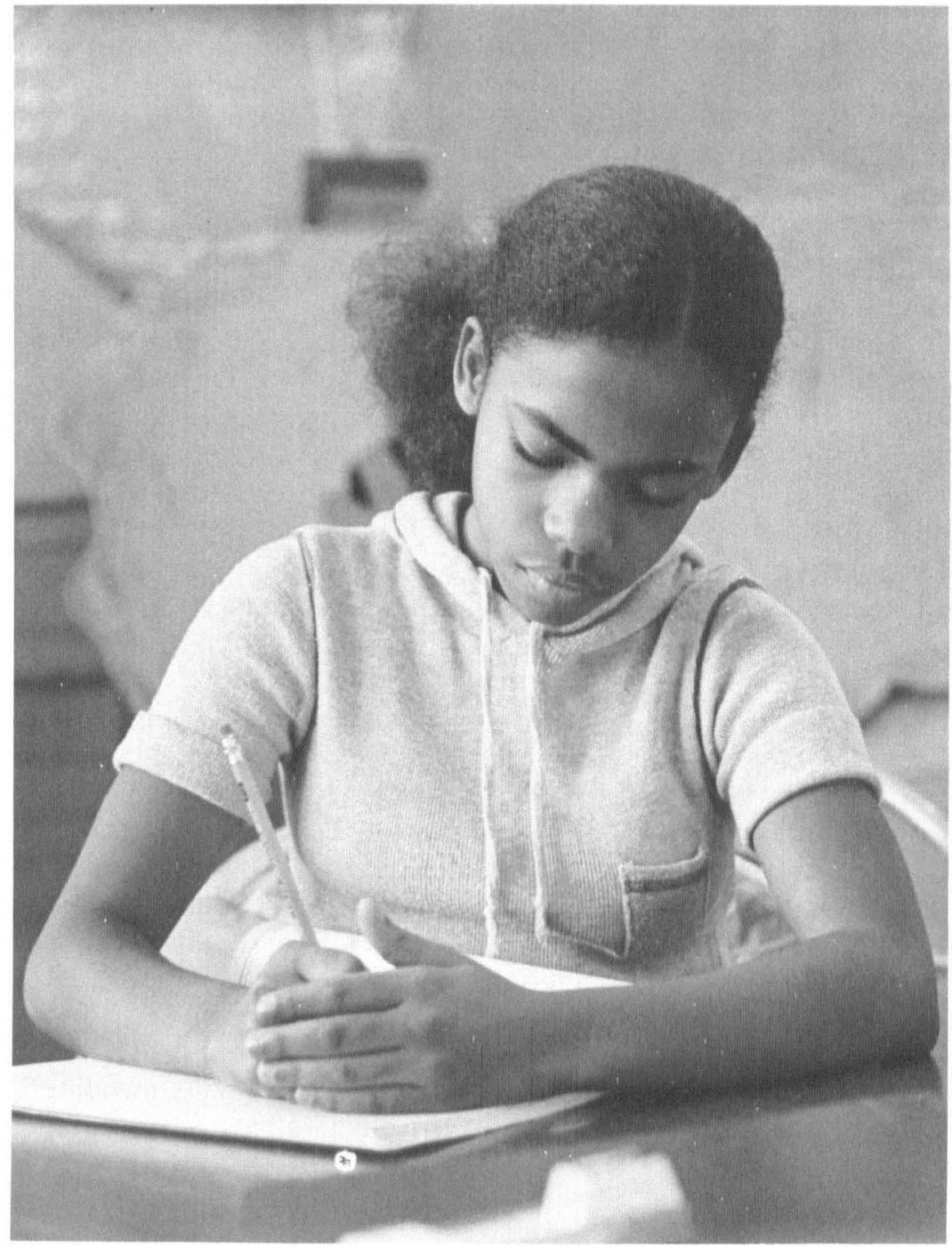

Photo by Elizabeth Crews

Improving the test-taking skills of LD adolescents is critical if they are to obtain academic success in mainstreamed settings. 
their feelings about tests relative to scoring procedures and grades in general. The student may need to ask questions and make statements such as these: "What do I have to do?" "I don't understand the directions." "How much time do I have?" "Could someone read the test to me?" "May I talk my answer into a tape recorder?" "There are too many things to do." "I am worried that I will fail."

The recommendation to be assertive is based on the assumption that students with learning or behavioral problems-and all students for that matter-have the right to receive clear test directions, to face test requirements that are fair or commensurate with their potential to succeed, and to receive extra assistance if they need it. Assertive behavior involves a new and perhaps high-risk role for learning-disabled students, but it is essential for their survival. Studies indicate that techniques involving separate and combined uses of modeling, role playing, verbal reinforcement, and rehearsal have been useful in increasing the assertive behavior of a variety of clinical populations, adolescents, and handicapped young persons. Social-skills training programs that focus on many behaviors classified as "assertive" are available for classroom use. For example, Stephens (1978) has identified these and other skills required for academic success; by providing models, corrective feedback, and reinforcement, he teaches them within the environment in which they function daily.

Rating scales (Deluty 1979) and training manuals (Lange and Jacabowski 1976; Liberman et al. 1975) are available for use as guides in establishing assertiveness training applied to student academic performance or test-related situations.

\section{Study and Test-taking Skills}

Study skills include organization of time and ideas, information processing, and critical analysis. Problems that present barriers to effective studying include: lack of retention, poor allocation of attention to tasks, inability to concentrate, procrastination, and cramming. These are problems of both nonhandicapped and learning-disabled students. In addition, however, learning-disabled adolescents may have problems in auditory and visual perception and sequencing, spatial organization, and memory; they may also be restless and have a low frustration level. These problems further impede their capacity to remember complex directions and to organize a pattern of study behaviors. 
Since independent study is a major academic activity and since learning-disabled students rarely spontaneously or independently develop this skill, training programs already existing in the school, such as reading labs, must be utilized for them. If this is not possible, the learning disabilities teacher should develop a program. Such a program should provide direct, intensive, and systematic instruction in efficient study and test-taking skills. Each skill-scheduling, organizing, listening, and note taking-should be task analyzed, taught, and practiced separately. The learning disabilities teacher should analyze each type of test situation the student will encounter-multiple choice, true-false, essay-and perhaps administer a survey of study skills (Brown and Holtzman 1956); numerous materials are available with which to teach these skills, some of which could be taped or otherwise adapted (Cohen et al. 1973).

\section{Developing Student Confidence and Control}

Before a test the teacher should identify the requirements of the task: directions, format, and criteria for passing; test topics, number and types of questions; time limits, and in some case, models of passing or acceptable answers. After the test the teacher should identify the student's errors in following directions, adhering to time limits, problem solving, sequencing, and so on, in order to provide information for future planning and practice.

Rehearsal may be a critical factor in student improvement. The more one practices a behavior, the greater the chances that one will perform well under actual conditions and will maintain and apply skills to new situations. Initially, such rehearsals should be short and involve relatively success-ensured tasks. The goal is the development of student confidence and control; the rehearsals then progress to longer and more difficult experiences.

Programming also involves creating an appropriate atmosphere for students for studying and test taking. For example, the classroom teacher's verbal instructions should be presented calmly and in a nonauthoritative tone and consist of short, single sentences. If repeated, they should be simply stated and consistent with prior statements. The learning specialist could model or tape such procedures for teachers in regular classes. In order to provide a sense of stability as well as a signal for action, the teacher should establish an organized and predictable set of test-taking conditions, such as arrangement of desks and availability of materials. During test taking, the teacher should 
provide a clock and approximations of time to be spent on each test section or question. Periodic breaks-one every ten to twenty minutes-would help students calm down before resuming the test.

\section{Self-Management Skills}

The ultimate goal of systematic training is to help learningdisabled adolescents cope with and manage their test-taking behaviors and use assertiveness and problem-solving or studying skills independently and in novel situations. Self-management implies that the student is actively involved in and contributes to his or her own improvement and eventually acts as an independent decision maker. The student must self-monitor, selfevaluate, and self-reinforce his behavior during tests. Self-regulation-the continual adjusting of behavior-implies that given a test or study task the student can independently identify when to be assertive, when to try to reduce anxiety, and when to engage in self-speech.

The teacher must assist in the development of the student's self-management skills. For example, usually it is the teacher who makes the decisions directly involved in the instructional process, but Lovitt (1973) has shown that many behaviors traditionally controlled by teachers could be managed by the students themselves, such as selecting, scheduling, presenting, reinforcing, recording, and evaluating. The teacher's role is that of a manager and facilitator whose job is to increase the student's competence and decrease his or her need for external controls.

A variety of individuals could be utilized to teach and support the student's use of self-management skills in school and at home. The school social worker could help establish procedures with those in the home, while the school counselor could assist in organizing and scheduling study groups and practice sessions at school. Paraprofessionals could provide assistance and supervision in self-instructional labs or study rooms. Peers acting as tutors and models could also be helpful since there is evidence that peers can act as effective teachers and that modeling and reinforcement are effective in changing other types of children's behavior.

\section{Role of Learning Disabilities Teacher/Consultant}

The learning disabilities teacher/consultant is the team leader of the training efforts, and he or she must be actively en- 
gaged in interacting with students and other professionals. First, the learning specialist analyzes the student's pattern of test performance, asking such questions as these: Does the test performance adequately reflect the knowledge and skills of the student? Are there wide discrepancies between the student's expectations and the results of test performances? Then, through discussions with the student and observations of him, the specialist identifies the student's feelings and perceptions of tests, patterns of study or preparation, behaviors during quizzes, and interactions with teachers concerning tests.

Second, the learning specialist deals with other professionals-the regular educator, counselor, social worker, and psychologist-to ascertain which sets of skills should be improved, whether problem solving, assertiveness, or study skills need attention, and whether or not treatment is warranted. When intervention is necessary, the learning disabilities consultant acts as a coordinator and designs a plan using available resources which employs strategies which he or she can implement in the resource room. Training to develop this complex repertoire of skills is frequently dependent on the services of a variety of individuals (see Table 1).

\section{Summary}

Increasing the study and test-taking skills of adolescents with learning disabilities is critical if such students are to obtain any measure of academic success in mainstreamed settings.

Based on research in behavior analysis, a multicomponent model is suggested which includes systematic, ongoing, and integrated training in the following five areas: reducing test anxiety; increasing assertiveness; improving problem-solving, study, and test-taking skills; and developing self-management skills. The goal of such programming is not only to enable students to learn effective skills but also to enable them to cope with their own problems and eventually to independently manage their own behaviors in the regular classroom.

The role of the learning disabilities consultant is active and multifaceted. It includes the ability to act dynamically as a team leader who can coordinate referrals, assessments, planning, service, and evaluation activities with other teaching and support personnel. It also requires being able to provide direct service, feedback to students on performance, and interaction with parents. 


\section{TABLE 1 \\ Improving the Test Taking Behavior of Students with Learning Disabilities}

\begin{tabular}{|c|c|c|}
\hline Deficits/Problems & Needed Skills & Personnel \\
\hline $\begin{array}{l}\text { Inadequate control of } \\
\text { anxiety and concen- } \\
\text { tration on task } \\
\text { (test anxiety) }\end{array}$ & $\begin{array}{l}\text { Anxiety management } \\
\text { skills }\end{array}$ & $\begin{array}{l}\text { Psychologist, } \\
\text { school psychologist, } \\
\text { social worker, men- } \\
\text { tal health profes- } \\
\text { sional, counselor, } \\
\text { university research } \\
\text { or clinical health } \\
\text { programs }\end{array}$ \\
\hline $\begin{array}{l}\text { Inability to clarify } \\
\text { directions, request help } \\
\text { or question tasks (non- } \\
\text { assertiveness or } \\
\text { aggression) }\end{array}$ & $\begin{array}{l}\text { Interpersonal or } \\
\text { assertive skills }\end{array}$ & $\begin{array}{l}\text { School psycholo- } \\
\text { gist, social worker, } \\
\text { special education } \\
\text { teacher, counselor, } \\
\text { community or } \\
\text { university-based } \\
\text { projects }\end{array}$ \\
\hline $\begin{array}{l}\text { Inability to attack } \\
\text { problems using an } \\
\text { organized sequence of } \\
\text { effective cognitive } \\
\text { behaviors }\end{array}$ & Problem solving & $\begin{array}{l}\text { Special education } \\
\text { personnel, class- } \\
\text { room teacher }\end{array}$ \\
\hline $\begin{array}{l}\text { Inability to control or } \\
\text { regulate oneself within } \\
\text { the environment }\end{array}$ & $\begin{array}{l}\text { Self-management } \\
\text { skills }\end{array}$ & $\begin{array}{l}\text { Counselor, social } \\
\text { worker, school psy- } \\
\text { chologist, reading } \\
\text { specialist, special } \\
\text { educator, parent, } \\
\text { paraprofessionals, } \\
\text { peers }\end{array}$ \\
\hline
\end{tabular}

\section{References}

Brown, W. F., and Holtzman, W. H. 1956. Surveys of study habits and attitudes. New York: Psychological Corporation.

Cohen, R. et al. 1973. Quest: academic skills program. New York: Harcourt Brace Jovanovich.

Deluty, R. H. 1979. Children's action tendency scale: a self report measure of aggressiveness, assertiveness, and submissiveness in children. Journal of Consulting and Clinical Psychology 47:6, pp. 1061-1071.

Lange, A. J., and Jakabowski, P. 1976. Responsible assertive behavior. Champaign, Illinois: Research Press. 
Liberman, R. P. et al. 1975. Personal effectiveness: guiding people to assist themselves and improve their social skills. Champaign, Illinois: Research Press.

Lovitt, T. C. 1973. Self management projects with children with behavioral disabilities. Journal of Learning Disabilities 6:135-150.

Meichenbaum, D. 1977. Cognitive-behavior modification: an integrative approach. New York: Plenum Press.

Spielberger, C. D. et al. 1977. The test anxiety inventory (TAI). Palo Alto, California: Consulting Psychologists Press.

Stephens, T. M. 1978. Social skills in the classroom. Columbus, Ohio: Cedars Press.

Wine, J. 1971. Test anxiety and direction of attention. Psychological Bulletin 76:92-104.

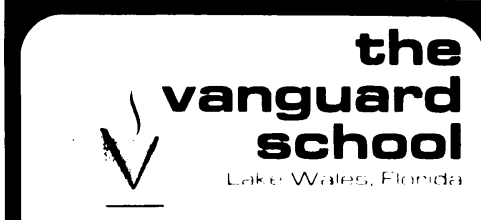

Residential - Coed Ungraded through High School

- Provides an academic, vocational, and social setting for the student who is experiencing learning disabilities, learning problems, and related adjustment difficulties.

- Through success oriented experiences, Vanguard endeavors to develop each individual's self-esteem.

- Through diagnostic prescriptive format, remedial education is personalized for each student.

Admission policies and proyrams are non-discriminatory in terms of race. color. creed. ethmic and national oriczin

For information

and literature contact:

Harry E. Nelson, Director

Box 928-A

Lake Wales, Florida 33853

813/676-6091

Day schools located in Paoli. Pa. and Coconut Grove. Fla.

Member: Natl. Assn. Private Schools for Exceptional Children.
For The Boy Who Needs Extra Help

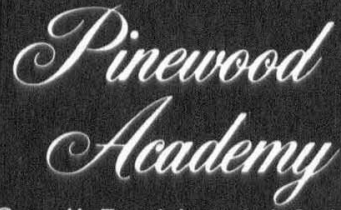

\section{A Small Residential School}

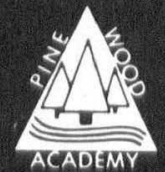

A unique, totally personalized approach to learning is employed, with special emphasis on individual instruction designed to meet the specific needs of boys from grades 6 to 12 , who are underachieving due to a specific language disability.

- COllege PREP

- small classes

- 1-1 TUTORING

- eXCELLENT FACILITIES

- FOREIGN STUDY-TRAVEL

- SKIING - ALPINE \& CROSS COUNTRY

- BACKPACKING

- NINE MONTH RESIDENTIAL SCHOOL

PINEWOOD ACA DEMY, Admissions Route 3, Eagle River, WI 54521 (715) $479-4114$ 